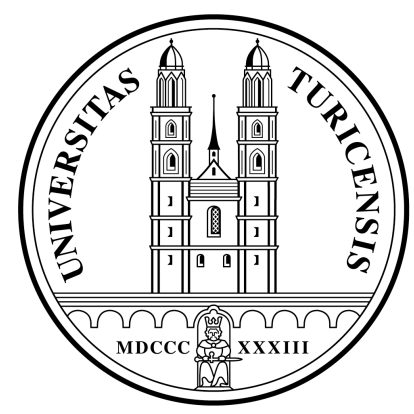

Institute for Empirical Research in Economics

University of Zurich

Working Paper Series

ISSN 1424-0459

Working Paper No. 150

Living in Two Neighborhoods - Social Interactions in the Lab

Armin Falk, Urs Fischbacher and Simon Gächter

May 2003 


\title{
LIVING IN TWO NEIGHBORHOODS - SOCIAL INTERACTIONS IN THE LAB*
}

\author{
ARMIN FALK \\ University of Zürich, CESifo, IZA and CEPR ${ }^{+}$ \\ URS FISCHBACHER \\ University of Zürich ${ }^{+}$ \\ SIMON GÄCHTER \\ University of St. Gallen and CESifo ${ }^{++}$
}

MAY 2003

Field evidence suggests that agents belonging to the same group tend to behave similarly, i.e., behavior exhibits social interaction effects. Testing for such effects raises severe identification problems. We conduct an experiment that avoids these problems. The main design feature is that each subject simultaneously is a member of two randomly assigned and economically identical groups where only members ('neighbors') are different. In both groups subjects make contribution decisions to a public good. We speak of social interactions if the same subject at the same time makes group-specific contributions that depend on their respective neighbors' contribution. Our results are unambiguous evidence for social interactions. A majority of subjects is very strongly influenced by the contributions of their respective neighbors. Roughly ten percent exhibit no social interactions.

Keywords: Social interactions, identification, experiments.

JEL-Classification: H41; C91; K42; H26.

\footnotetext{
* This paper is part of the EU-TMR project ENDEAR (FMRX CT98-0238). Lukas Baumann, Michael Bolliger, Esther Kessler and Christian Thöni provided very valuable research assistance. We received helpful comments from Gary Charness, Alan Durell, Stefano Della Vigna, Claudia Keser, Manfred Königstein, Michael Kosfeld, Charles Manski, Shepley Orr, Ekkehart Schlicht, Jason Shachat, Frans van Winden, and participants at seminars and conferences in Amsterdam, Berlin, Boston, Essen, IBM T.J Watson (Yorktown Heights, USA), Jena, London, Munich, Norwich, St. Gallen, Venice, and Zürich. Simon Gächter gratefully acknowledges the hospitality of CES Munich while working on this paper.

+ Institute for Empirical Research in Economics, Blümlisalpstrasse 10, CH-8006 Zürich. E-mail: falk@iew.unizh.ch.

+ Institute for Empirical Research in Economics, Blümlisalpstrasse 10, CH-8006 Zürich. E-mail: fiba@iew.unizh.ch.

${ }^{++}$FEW-HSG, Varnbüelstrasse 14, CH-9000 St. Gallen. E-mail: $\underline{\text { simon.gaechter@unisg.ch }}$
} 


\section{INTRODUCTION}

It is a long-standing and fundamental problem of the social sciences to understand whether and how humans are influenced by the behavior exhibited by the members of the social group they belong to. There is now mounting evidence that neglecting such social interactions (or peer and neighborhood effects) hinders a proper understanding of important economic and social problems: Among other phenomena, social interactions determine criminal behavior [Glaeser, Scheinkman and Sacerdote 1996], affect the dynamics of urban poverty and crime [Case and Katz 1991; Ludwig, Duncan, and Hirschfield 2001; Katz, Kling, and Liebman 2001], influence welfare participation [Bertrand, Luttmer, and Mullainathan 2000] and work place behavior [Ichino and Maggi 2000; Falk and Ichino 2003] and have an impact on academic success [Sacerdote 2001].

Identifying social interaction effects with the usually available field data has proved to be notoriously difficult [Manski 1993, 2000; Akerlof 1997; Glaeser and Scheinkman 2001]. Among the problems that need to be solved are (i) identifying the reference group for which social interaction effects are sought to be established (e.g., by identifying language networks as in Bertrand et al. [2000]), (ii) circumventing the problem of self-selection of group members by investigating randomly composed groups (e.g., Sacerdote [2001]), (iii) controlling for correlated effects that affect all group members in a similar way, and (iv) controlling for contextual effects like exogenous social background characteristics of group members. The latter two problems require very rich data sets, possibly at the individual level (see, e.g., Ichino and Maggi [2000]).

In this paper we take a different route than the papers discussed above and provide a laboratory experiment to study the phenomenon of social interactions. We argue that the experimental laboratory provides the researcher with a valuable tool to study social interactions because it guarantees more control than any other available data source. The ideal data set would observe the same individual at the same time in different neighborhoods, which are identical - apart from different neighbors. Obviously, this is impossible in the field. By contrast, in the lab it is possible to come very close to this 'counterfactual state'. In our experiment, we are able to observe decisions of the same subject at the same time in two economically identical environments. The only reason to behave differently in these two environments is social interactions, i.e., the fact that a person is systematically affected by the behavior of his neighbors in the two environments. Our design therefore circumvents the 
above-mentioned identification problems. Using the terminology of Manski [2000], in our study reference groups are well-defined; the set-up avoids the self-selection problem; subjects make decisions in two economically identical environments, which controls for correlated effects; the decision problem is abstractly framed and decisions are taken anonymously, which avoids contextual effects. Moreover, our laboratory approach has the added advantage of minimizing measurement errors.

The decision variable in the two environments (group 1 and group 2) is a voluntary contribution to a standard linear public good. We have chosen a public goods environment mainly because many economically important decisions that are potentially affected by social interactions are characterized by external effects, such as compliance with social norms or behavior at the workplace. These decisions can be modeled as public goods games. We speak of 'social interactions' if subjects differentiate their contributions depending on their neighbors' contributions in their respective groups.

Our data lend strong and unambiguous support for the importance of social interactions: The same subject contributes more to group 1 than to group 2 if the average contributions of his neighbors in group 1 are higher than those of the neighbors in group 2 and vice versa. Econometric analysis reveals further that behavior of neighbors in group 2 has only a very limited impact on decisions in group 1 and vice versa.

We also analyze behavior at the individual level and find that most subjects exhibit strong social interaction effects in their contribution behavior. Yet there is substantial individual heterogeneity. Roughly ten percent of the subjects display no social interactions at all.

Finally we compare the contribution patterns in the design where subjects are members of two groups with the pattern that evolves if subjects are members of only one group. It turns out that the contribution patterns are almost identical. This is an important result insofar as it shows that the abstraction to study public goods behavior in games where people are only acting in one group is a good approximation for the behavior outside the lab where subjects typically interact in multiple groups. Our paper therefore contributes to the understanding of social interactions as well as to the understanding of voluntary contributions in general.

Our paper is organized as follows. In Section II we will describe our experimental designs. Section III contains our hypotheses and Section IV presents the results at an aggregate and an individual level. It also contains the comparison of contribution patterns in the designs with multiple and single memberships, respectively. Section V concludes. 


\section{EXPERIMENTAL DESIGN AND PROCEDURES}

\section{A. Description of the design}

The philosophy and novel feature of our experimental design is to put the same person at the same time into two different, yet economically identical environments. Thus, it is only the behavior of other neighbors in these environments that can explain possible behavioral differences in the two environments. Finding such a different behavior is therefore evidence for social interactions.

The implementation of the 'two neighborhood' design was straightforward (see Figure I): Nine subjects formed a so-called matching group. Within such a matching group, all subjects were simultaneously members of two neighborhoods called 'groups'. Subjects were told that they were members of a 'group 1' and a 'group 2' (see the instructions in the Appendix). The two groups were formed such that each subject had two different neighbors in each group. For example, in Figure I, subject 4 formed a group with subjects 1 and 7 and another group with subjects 5 and $6 .{ }^{1}$ Likewise, subject 9 formed a group with subjects 3 and 6 and another group with subjects 7 and 8 .

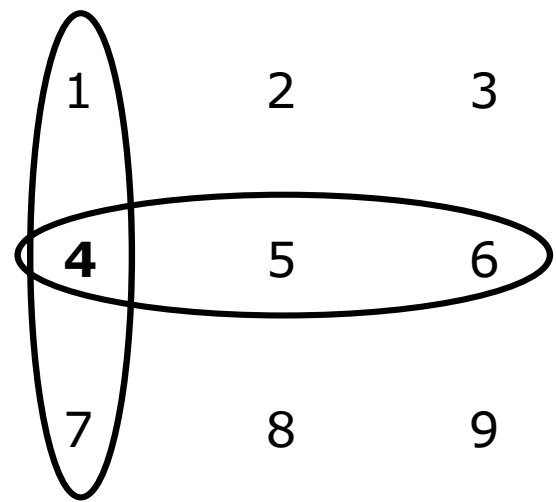

FIGURE I

OUR TWO-GROUP DESIGN

Note: Numbers represent different subjects in the experiment.

Within each of the two groups subjects had to make a contribution to a standard linear public good. We chose a public goods environment for two reasons. First, many economically

\footnotetext{
${ }^{1 .}$ In the experiment subjects had no labels. We use the numbering of subjects in Figure I only for expositional reasons.
} 
important decisions that are potentially affected by social interactions are characterized by external effects, like tax compliance, compliance with social norms or behavior at the workplace. This type of situations can be modeled as public goods games (see, e.g., Coleman [1990]). Second, our design is biased against finding a social interaction effect, since, as we show below, the unique strict equilibrium of the stage game (under standard preferences) is one in dominant strategies. We would like to point out, however, that the general idea of the twogroup design is not confined to public goods games. Our two-group design can be applied in other contexts as well, e.g., in coordination games. Social interactions in games with multiple equilibria would imply that the same subject coordinates on different equilibria, depending on the respective neighbors' behavior.

The public goods of the two groups were technologically completely independent of each other. Each subject was endowed with 20 tokens in each group and could invest up to 20 tokens into the public good of the respective group. Let $G_{i}^{1}$ be the set of the members of player $i$ 's group 1 and let $G_{i}^{2}$ be the set of the members of player $i$ 's group 2 . For example, individual 4 from Figure I lives in the two neighborhoods $G_{4}^{1}=\{1,4,7\}$ and $G_{4}^{2}=\{4,5,6\}$. Let $c_{i}^{1}\left(c_{i}^{2}\right)$ denote i's voluntary contribution to group 1 (group 2). For both groups the following budget constraints had to hold: $0 \leq c_{i}^{1} \leq 20$ and $0 \leq c_{i}^{2} \leq 20$. If a subject decided, e.g., to invest 10 tokens in group 1 she could nevertheless only invest at most 20 tokens in group 2. Any token not invested in the public good of the respective group was automatically invested into a private good. Thus, for each subject $i$ the payoff function was as follows:

$$
\pi_{i}=\left(20-c_{i}^{1}\right)+\alpha \sum_{j \in G_{i}^{1}}^{3} c_{j}^{1}+\left(20-c_{i}^{2}\right)+\alpha \sum_{k \in G_{i}^{2}}^{3} c_{k}^{2},
$$

where $j$ and $k$ are indices for neighbors of group 1 and group 2, respectively. In our experiment, $\alpha$, the marginal per capita return of the public good, was set equal to 0.6 ; the social marginal return therefore was 1.8. Thus, since $\alpha<1<3 \alpha$, a selfish individual has a dominant strategy to free ride completely, while total payoffs are maximized if everybody fully invests into the group account.

Subjects were randomly allocated to the groups and remained paired for 20 periods. The subjects knew this. At the beginning of each period, subjects had to make their contribution decisions for both public goods on the same screen. The screen was separated into two vertical 
parts (called 'group 1' and 'group 2') and contained an input box for each group. On the same screen where subjects had to make their simultaneous contribution decisions, subjects were also informed for both group 1 and group 2 about (1) the average contribution of all respective group members (2) their respective incomes in the previous period and (3) the respective average group contribution over all previous periods. Full anonymity between subjects was maintained throughout the whole experiment. The experiment was computerized using the experimental software z-Tree [Fischbacher 1999].

The novel feature of our two-group experiment is that subjects are simultaneously members of two groups. This design feature is without precedent, which is remarkable because in reality multiple memberships are the rule rather than the exception. People are, e.g., at the same time taxpayers and voters, or members of different sports clubs and so on. It is an interesting and open question whether the fact of being in various groups vs. being just in one group systematically produces different contribution behaviors. If this were true, many findings of the experimental public goods literature would be in question.

In order to compare contribution patterns in the two-group design with behavior in a standard public goods game, we also conducted a standard single-group linear public goods experiment with three group members ('one-group' design). This experiment was exactly the same as our two-group design except that subjects were only members of a single-group and got only information about the average contribution of their group members. The payoff function was exactly the same as (1), except that there was only one public good to which they could contribute and from which subjects received a payoff.

\section{B. Discussion of the two-group design}

The purpose of our study is to identify social interaction effects, which requires extensive control. We argue that a laboratory environment allows a degree of control, which is impossible to reach in the field.

First, we control for any self-selection effect. This is achieved by the fact that subjects were randomly allocated to their groups and that we observe the same subject's behavior in two different groups. Even without random allocation, this latter feature alone circumvents selfselection problems.

Second, we control for correlated effects, i.e., for the possibility that neighborhood characteristics influence behavior [Manski 1993]. In our experiment the two environments in 
which subjects make their decisions are economically exactly identical. In each group all subjects have the same action space, the same endowment and budget constraint, the same information conditions and the same material incentives. Both groups are completely independent of each other, i.e., a decision in group 1 does not change the endowment, the action space or the incentives in group 2. Moreover, groups are equal in size and each neighbor faces the same economic incentives. The two-group design also controls for correlated effects that might be caused by the fact that different sessions are conducted at different dates and times. Even more importantly, it controls for experience and learning. When a subject decides how much to contribute to the two groups she has exactly the same experience for both decisions. This cannot be achieved in a one-group design.

Third, we control for contextual effects, i.e., for the fact that a person may show a different behavior in the two groups because of the socio-economic composition of the two groups [Manski 1993]. Control in this respect is ensured by the fact that experimental subjects were very homogenous with respect to their socio-economic background and, more importantly, interaction was anonymous.

Fourth, while in the field one can only hypothesize about the relevant group of comparison and try to find some good proxy (language group, neighbors of the same block, zip code etc.) the lab environment controls the available information. Subjects receive information only about the behavior of those groups they actually belong to. This implies, e.g., that subjects cannot compare to any other group. ${ }^{2}$ Fifth, our computerized lab environment excludes measurement errors.

\section{Procedures}

In total, 174 subjects participated in our experiments. In the two-group design 126 subjects, who made 5040 contribution decisions, took part. They formed 14 independent matching groups of nine members each (see Figure I). In the one-group experiments 48 subjects participated who formed 16 independent groups. No subject participated in more than one treatment. The experiments were conducted in the computer lab at the University of St. Gallen. Most subjects were first-semester undergraduate students of law, economics and

\footnotetext{
2. Relaxing this information condition could be an interesting treatment condition since it would allow insights with whom subjects choose to compare with. This could be implemented, e.g., by giving subjects the possibility to inform themselves about the behavior of groups they do not belong to.
} 
business administration. None of them had participated in a public goods experiment before. After reading the instructions subjects had to solve a set of computerized control questions that tested their understanding of payoff calculations. The experiment started only after all participants had answered all questions correctly.

During the experiments income was counted in 'Guilders', which were translated to Swiss Francs at the end of the experiment (at an exchange rate of 1 Guilder $=3$ Rappen). On average, subjects earned 33 Swiss Francs $(\approx$ US\$ $22 \approx € 22)$. The experiments lasted approximately 70 to 80 minutes.

\section{HYPOTHESES}

We start with the standard economic hypothesis. Under the assumption of rationality and selfishness, the standard hypothesis predicts zero contributions to both public goods, i.e., full free riding. In the stage games this is obvious since it is a dominant strategy to contribute nothing. In our finitely repeated games it holds with backward induction.

In contrast to the standard economic prediction it is known from many public goods experiments that some people cooperate, at least in early periods of an experiment. Is the mere fact of observing cooperation in our experiment already an indication for the existence of social interaction? The answer to this question depends on the motives and the pattern of cooperation. For example, motives like "warm glow" might account for non-zero contributions (see e.g., Andreoni [1990], [1995a], [1995b], and Palfrey and Prisbrey [1997]). Likewise simple errors may lead to positive contributions. However, both warm glow as well as errors, are independent of the contributions of other group members. A person who contributes for reasons of warm glow contributes the same amount in both groups, independent of the cooperation levels in these groups. To the contrary, social interactions mean that subjects' contributions are affected by the contributions of their neighbors. This conditional cooperation pattern has been discussed, e.g., in Sugden [1984], Andreoni [1995b], Croson [1998], Keser and van Winden [2000] or Fischbacher et al. [2001]. Applied to our context it requires that the same individual contributes more in the neighborhood that has contributed more in the past.

To state the alternative hypotheses more formally, let $c_{i}^{1}$ denote subject $i$ 's contribution in period $t$ to group 1 and let $g_{i}^{1}$ denote the average contribution of $i$ 's neighbors in group 1 in 
period $t-1$. Analogously, $c_{i}^{2}$ denotes subject $i$ 's contribution in period $t$ to group 2 and $g_{i}^{2}$ denotes the average contribution of $i$ 's neighbors in group 2 in period $t-1$. Social interactions require that $\operatorname{corr}\left[\left(c_{i}^{1}-c_{i}^{2}\right),\left(g_{i}^{1}-g_{i}^{2}\right)\right]>0$, i.e., the larger the contribution difference of the neighbors of group 1 and group 2 in the previous period, the larger is the difference in current contributions of a group member to the two groups. In contrast, if there are no social interactions, we should see no such correlation. This may be the case either if there is full free riding $\left(c_{i}^{1}=c_{i}^{2}=0\right)$ or if people - e.g., for reasons of a warm glow - are willing to make positive contributions to the public good, which are however independent of $\left(g_{i}^{1}-g_{i}^{2}\right)$. We summarize our hypotheses as follows:

No SOCIAL INTERACTIONS HYPOTHESIS. The difference in the contributions are unrelated to the difference in the neighbors' contributions in the previous period, i.e., $\operatorname{corr}\left[\left(c_{i}^{1}-c_{i}^{2}\right),\left(g_{i}^{1}-\right.\right.$ $\left.\left.g_{i}^{2}\right)\right]=0$

SOCIAL INTERACTIONS HYPOTHESIS. The larger the difference in contributions of neighbors in group 1 and group 2 in the previous period, the larger is the difference in current contributions of a group member to the two groups, i.e., corr $\left[\left(c_{i}^{1}-c_{i}^{2}\right),\left(g_{i}^{1}-g_{i}^{2}\right)\right]>0$. Accordingly, the likelihood in the current period to contribute more to group 1 than to group 2 depends positively on $\left(g_{i}^{1}-g_{i}^{2}\right)$ (and vice versa for group 2$)$.

\section{RESULTS}

In our discussion of the results we first present data at the aggregate level and for each of our fourteen matching groups. We then identify subjects' individual proclivity for exhibiting social interaction effects. We conclude this section by comparing the cooperation patterns in our two-group design with those in the single-group design.

\section{A. Aggregate analysis}

Our main result is that the data strongly reject the No Social Interactions Hypothesis in favor of the Social Interactions Hypothesis. On average, subjects contribute more to the group 
that has contributed more in the previous period. Support for this result comes from Figures II - IV and Table I. Figure II plots the average difference in current contributions $\left(c_{i}^{1}-c_{i}^{2}\right)$ as a function of the difference of the neighbors' contributions in the respective groups in the previous period $\left(g_{i}^{1}-g_{i}^{2}\right)$. While the No Social Interactions Hypothesis predicts this graph to fluctuate around $\left(c_{i}^{1}-c_{i}^{2}\right)=0$, we find a very strong positive relationship between $\left(c_{i}^{1}-c_{i}^{2}\right)$ and $\left(g_{i}^{1}-g_{i}^{2}\right)$. Put differently, people tend to contribute more to group 1 than to group 2 (i.e., $\left.c_{i}^{1}>c_{i}^{2}\right)$ if $g_{i}^{1}>g_{i}^{2}$ and vice versa.

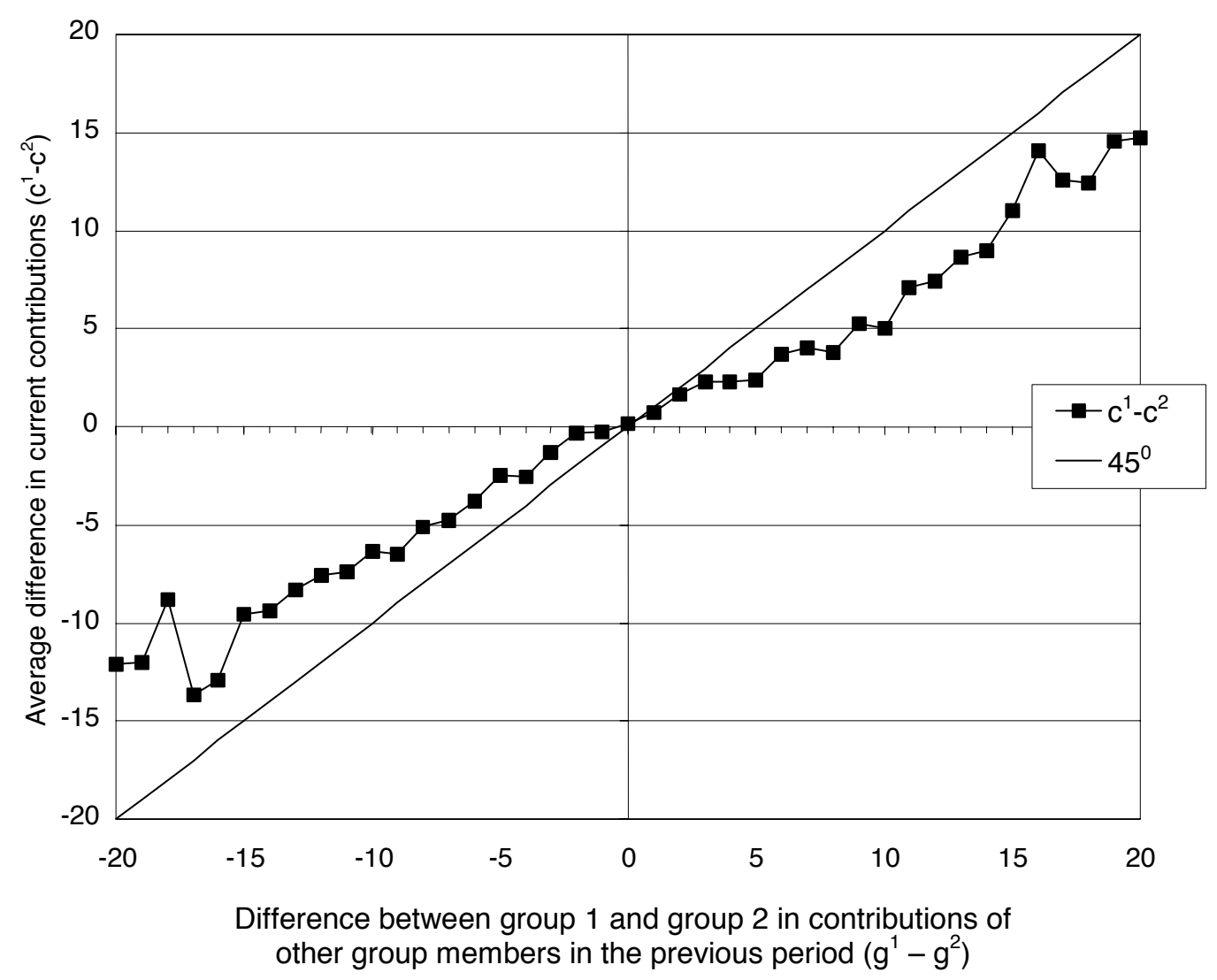

FIGURE II

SOCIAL INTERACTION EFFECTS: DIFFERENCE IN OWN CONTRIBUTION AS A FUNCTION OF THE NEIGHBORS' CONTRIBUTIONS IN THE TWO GROUPS

Figure III looks at the social interaction effects from another angle. As a function of $\left(g_{i}^{1}-g_{i}^{2}\right)$ it shows three graphs, indicating the probability of contributing more to group 1 than to group 2, more to group 2 than to group 1 and contributing the same in both groups. Figure III is based 
on all data from all matching groups and uses intervals for $\left(g_{i}^{1}-g_{i}^{2}\right)$. The intervals were determined in a way such that each interval includes roughly the same number of observations. For each interval the three graphs add up to a probability of 1 .

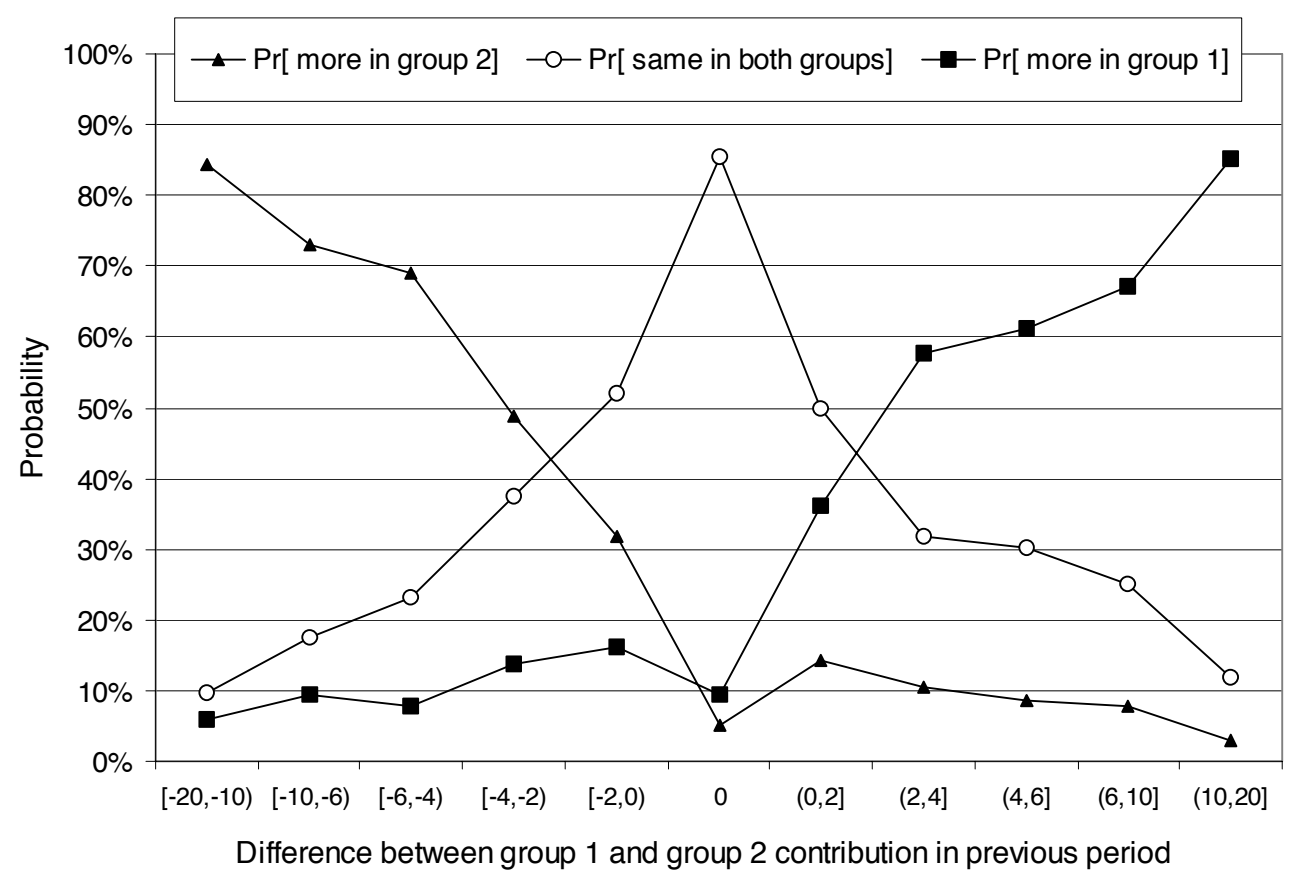

FIGURE III

THE PROBABILITY OF CONTRIBUTING MORE TO GROUP 1, MORE TO GROUP 2 OR THE SAME AMOUNT IN BOTH GROUPS AS A FUNCTION OF $\left(g_{i}^{1}-g_{i}^{2}\right)$

Several observations can be made in Figure III. First, the probability of contributing more to group 1 than to group 2 is very low if $g_{i}^{1}<g_{i}^{2}$ and is slightly increasing in $\left(g_{i}^{1}-g_{i}^{2}\right)$. For $g_{i}^{1}$ $-g_{i}^{2}=0$, the probability is about 10 percent. For $\left(g_{i}^{1}-g_{i}^{2}\right)>0$ the probability is strongly and monotonously increasing in $\left(g_{i}^{1}-g_{i}^{2}\right)$, reaching roughly 85 percent for high values of $\left(g_{i}^{1}-\right.$ $\left.g_{i}^{2}\right)$. Second, the probability to invest more in group 2 than in group 1 as a function of $\left(g_{i}^{1}-\right.$ $g_{i}^{2}$ ) is almost exactly the mirror image of the probability to invest more in group 1 . Third, the probability to contribute the same amount in both groups is the higher the smaller the absolute value of $\left(g_{i}^{1}-g_{i}^{2}\right)$. It reaches its maximum of roughly 85 percent for $g_{i}^{1}-g_{i}^{2}=0$. Note that even for very small deviations from $g_{i}^{1}-g_{i}^{2}=0$ (intervals [-2,0) and $(0,2]$ ), the probability 
sharply drops from 85 to about 50 percent. Taken together Figure III strongly supports the existence of social interaction.

Remember that our design involves matching groups of nine subjects. These matching groups form the strictly independent observations of our data set. Figure IV looks at our hypotheses at the level of matching groups by providing scatter plots of $\left(c_{i}^{1}-c_{i}^{2}\right)$ as a function of $\left(g_{i}^{1}-g_{i}^{2}\right)$ for each of our fourteen matching groups.
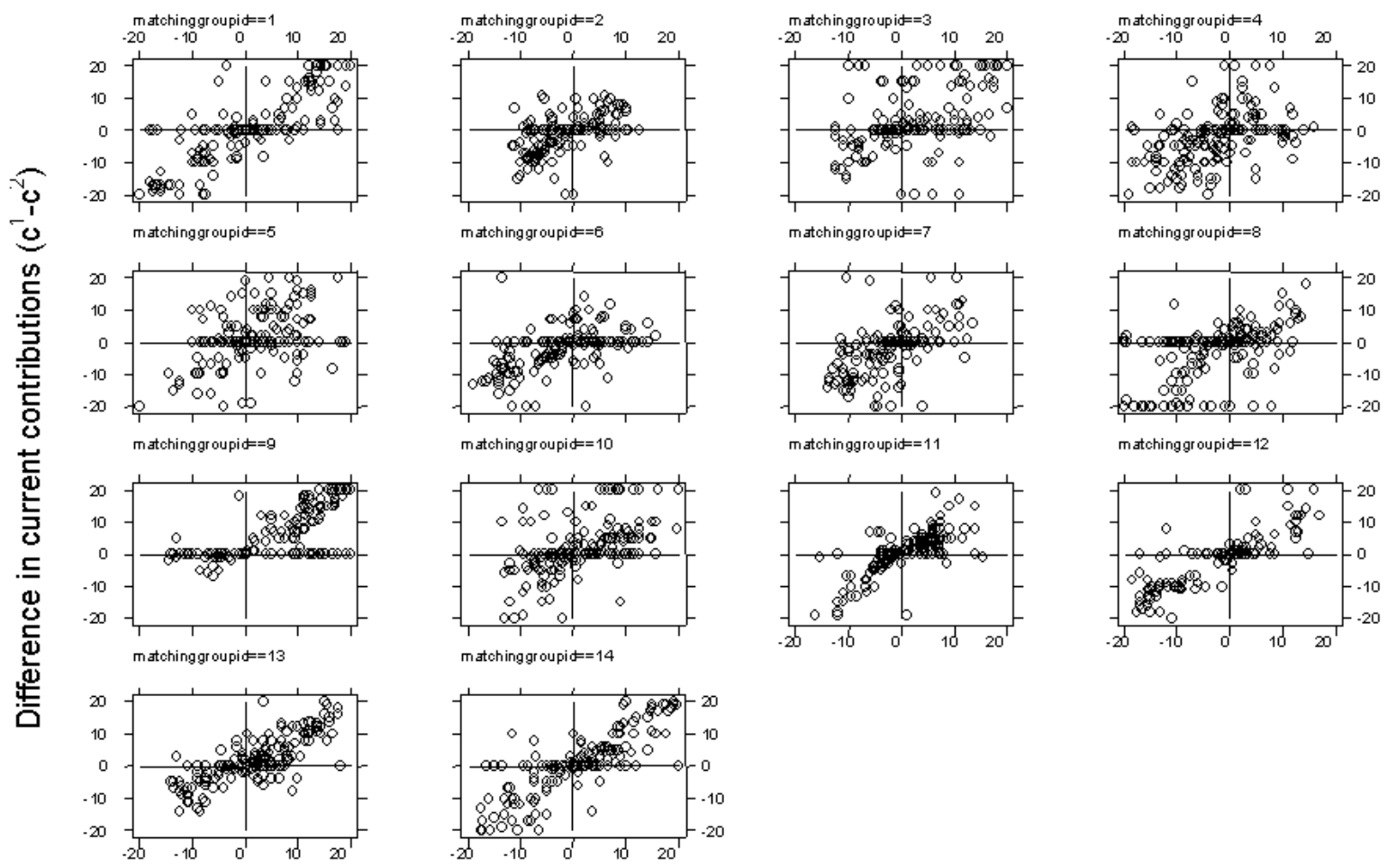

matchinggroupid= $=12$
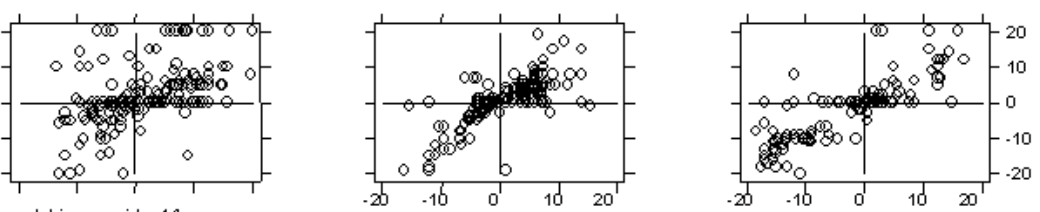

Between-group contribution difference of other members $\left(g^{1}-g^{2}\right)$

FIGURE IV

SOCIAL INTERACTION EFFECTS BETWEEN GROUP 1 AND GROUP 2 PER MATCHING GROUPS

The first observation from Figure IV is that the relationship we find at the aggregate level holds for all fourteen matching groups. In all our matching groups the bulk of observations is in the upper right and the lower left quadrants (defined by $\left(c_{i}^{1}-c_{i}^{2}\right)=0$ and $\left.\left(g_{i}^{1}-g_{i}^{2}\right)=0\right)$. Thus, the observation of Figure II is not an artifact of aggregation. Figure IV also reveals that in all matching groups there is a certain number of contribution decisions with $c_{i}^{1}-c_{i}^{2}=0$ also for 
$g_{i}^{1}-g_{i}^{2} \neq 0$. These are contribution decisions that are unaffected by social interactions. We will return to this observation in our analysis of individual behavior.

In the following we test the statistical significance of the observed social interaction effects. As a first test, note that we observe in all 14 matching groups a strictly positive correlation between $\left(c_{i}^{1}-c_{i}^{2}\right)$ and $\left(g_{i}^{1}-g_{i}^{2}\right)$. With no social interactions the probability of finding a strictly positive correlation in one matching group is (slightly smaller than) $1 / 2$. The probability of finding a positive correlation in all 14 matching groups without social interaction is therefore smaller than $1 / 2^{14} \approx 0.00006$. As a second test, Table I (first column) records the results of a robust OLS regression analysis. Since within a matching group contributions are not independent, we have calculated robust standard errors that allow for correlated errors within matching groups. The dependent variable is $\left(c_{i}^{1}-c_{i}^{2}\right)$. This variable is regressed on $\left(g_{i}^{1}\right.$ $-g_{i}^{2}$ ), i.e., the difference in neighbor's contributions in the previous period. To study possible time effects, we also include the period index and interact "period" with $\left(g_{i}^{1}-g_{i}^{2}\right)$.

The regression strongly supports our previous arguments. The coefficient on $\left(g_{i}^{1}-g_{i}^{2}\right)$ is positive and the robust standard errors are extremely low, which leads to a very high $t$-value $(t$ $=11.25)$. Moreover, the observed social interaction effect does not vanish with more experience, since the interaction term period* $\left(g_{i}^{1}-g_{i}^{2}\right)$ is not significantly different from zero. $^{3,4}$

So far we have shown that subjects differentiate their contributions according to the contributions of their respective neighbors such that $\operatorname{corr}\left[\left(c_{i}^{1}-c_{i}^{2}\right),\left(g_{i}^{1}-g_{i}^{2}\right)\right]>0$ holds. However, we have not yet looked at how this positive correlation comes about. In particular it is interesting to know whether the behavior of the neighbors in group 2 has an impact on contribution behavior in group 1 and vice versa. For example, it could be that the more the neighbors contribute in group 2 the less a person is inclined to contribute in group 1 . In order to study the impact of the neighbors' contributions in group 1 (group 2) on own contributions in group 2 (group 1) we report two further regressions in Table I.

\footnotetext{
${ }^{3 .}$ Because the groups are identical we expect an intercept of zero (measured by the constant) and we do not expect that the intercept will be different from zero in later periods (measured by the variable 'period'). This is also what we observe.

${ }^{4 .}$ Regressions restricted to single periods provide a further test for the stability of our results over time. For all periods, the regressions have a highly significant coefficient for $\left(g_{i}^{1}-g_{i}^{2}\right)$ and an insignificant constant.
} 
TABLE I

SOCIAL INTERACTIONS: EXPLAINING CONTRIBUTIONS WITH THE BEHAVIOR OF NEIGHBORS

Dependent variable

\begin{tabular}{|c|c|c|c|}
\hline $\begin{array}{l}\text { Independent } \\
\text { variable }\end{array}$ & $c_{i}^{1}-c_{i}^{2}$ & $c_{i}^{1}$ & $c_{i}^{2}$ \\
\hline$g_{i}^{1}-g_{i}^{2}$ & $\begin{array}{c}0.605 * * * \\
(0.054)\end{array}$ & & \\
\hline period & $\begin{array}{c}0.007 \\
(0.023)\end{array}$ & $\begin{array}{c}-0.103 * * * \\
(0.018)\end{array}$ & $\begin{array}{c}-0.121 * * * \\
(0.024)\end{array}$ \\
\hline period $*\left(g_{i}^{1}-g_{i}^{2}\right)$ & $\begin{array}{l}0.005 \\
(0.005)\end{array}$ & & \\
\hline$g_{i}^{1}$ & & $\begin{array}{c}0.750 * * * \\
(0.061)\end{array}$ & $\begin{array}{c}0.069 \\
(0.045)\end{array}$ \\
\hline$g_{i}^{2}$ & & $\begin{array}{c}0.021 \\
(0.037)\end{array}$ & $\begin{array}{c}0.663 * * * \\
(0.046)\end{array}$ \\
\hline constant & $\begin{array}{l}-0.022 \\
(0.416)\end{array}$ & $\begin{array}{c}2.901 * * * \\
(0.672)\end{array}$ & $\begin{array}{c}3.418 * * * \\
(0.776)\end{array}$ \\
\hline & $\begin{aligned} \mathrm{N} & =2394 \\
\mathrm{~F}(3,13) & =144.9^{* * *} \\
\mathrm{R}^{2} & =0.44\end{aligned}$ & $\begin{aligned} \mathrm{N} & =2394 \\
\mathrm{~F}(3,13) & =101.4^{* * *} \\
\mathrm{R}^{2} & =0.46\end{aligned}$ & $\begin{array}{c}\mathrm{N}=2394 \\
\mathrm{~F}(3,6)=185.0^{* * *} \\
\mathrm{R}^{2}=0.37\end{array}$ \\
\hline
\end{tabular}

Note: $\left(c_{i}^{1}-c_{i}^{2}\right)$ measures own difference in contribution to group 1 and group 2 in period $t ;\left(g_{i}^{1}-g_{i}^{2}\right)$ is the difference in neighbors' contributions in group 1 and group 2 in $t-1$; *** denotes significance at the 1-percent level; robust standard errors clustered on matching groups in parentheses.

The regression in column 2 shows that while the contribution decision in group $1\left(c_{i}^{1}\right)$ is strongly and positively influenced by the behavior of neighbors in group $1\left(g_{i}^{1}\right)$, the behavior of neighbors in group $2\left(g_{i}^{2}\right)$ has only a slightly positive and clearly insignificant effect. Likewise, the third regression model shows that $c_{i}^{2}$ is strongly influenced by $g_{i}^{2}$ but hardly so by $g_{i}^{1} \cdot 5$ In both models the coefficient on 'period' is negative and highly significant. This indicates the general downward trend in contributions (compare also Figure VI).

Taken together the regressions in columns 2 and 3 reveal that there are hardly any spillover effects from one neighborhood to the other. A subject's decision to contribute in

\footnotetext{
5. Note that the correlation between, e.g., $c_{i}^{1}$ and $g_{i}^{1}$ is not a strict test for the existence of social interactions. Finding such a correlation could be due to, e.g., correlated effects with respect to time. If all subjects for whatever reason would reduce their contributions from one period to the next we would find such a correlation. In our twogroup design we observe two contribution decisions at the same time, thereby ruling out correlated time effects. Ruling out these correlated effects is impossible in a standard one-group design.
} 
group 1 is not significantly influenced by the behavior of group 2 neighbors and vice versa. This is an interesting result. It suggests that when deciding on an action that affects people in a particular group, behavior of this group's members is very important but behavior of people in other groups is largely irrelevant. For example, the willingness of a person to contribute to his tennis club may not be affected by the behavior of his fellow soccer club members. As long as groups are separated and external effects are confined to a particular group, we expect social interactions to be confined to that very group as well.

\section{B. Individual heterogeneity}

In our aggregate analysis we have provided unambiguous evidence for the importance of social interaction effects. On average, subjects are very strongly influenced by the contribution decisions of their respective neighbors. In this section we study social interactions at the individual level. As the preceding figures already suggest, it is not likely that all subjects display the same interaction effects. Rather we expect that some subjects are strongly affected by social interactions while others are affected to a lesser extent - if at all. Figure V investigates this individual heterogeneity. It shows the relative frequency of subjects who exhibit a particular intensity level of social interactions. This intensity level is measured with simple OLS-regressions for each individual, where $c_{i}^{1}-c_{i}^{2}$ is regressed on $g_{i}^{1}-g_{i}^{2}$ for periods 2 to 20 , setting the constant to zero. Figure $\mathrm{V}$ shows the distribution of these coefficients, where each individual coefficient is rounded to a multiple of 0.2 . A coefficient equal to one means that a subject perfectly matches the difference $g_{i}^{1}-g_{i}^{2}$, while a coefficient of zero implies no social interactions.

Figure V offers several interesting insights. First, 89 percent of the subjects show a positive coefficient. Thus, in line with our previous arguments, the majority of individuals shows social interactions. Second, there is pronounced individual heterogeneity, i.e., subjects are very differently affected by social interactions. Third, 14 subjects (11 percent) have a (rounded) coefficient of zero. Five of these 14 subjects have a coefficient of exactly zero (see the light gray part of the column at 0$)^{6}{ }^{6}$ Thus, roughly 11 percent of the subjects show no social interactions at all.

\footnotetext{
6. Of these five subjects three are completely selfish, i.e., they always defect while two always contribute independently of the other group members' decisions.
} 
The finding of two classes of subjects, those whose behavior is influenced by the behavior of their neighbors and those whose behavior is independent of others is consistent with the assumption put forward in Glaeser et al. [1996]. In their model there is a group of agents whose decision to become criminal is influenced by the behavior of their neighbors while others, the so-called 'fixed agents', are affected by others.

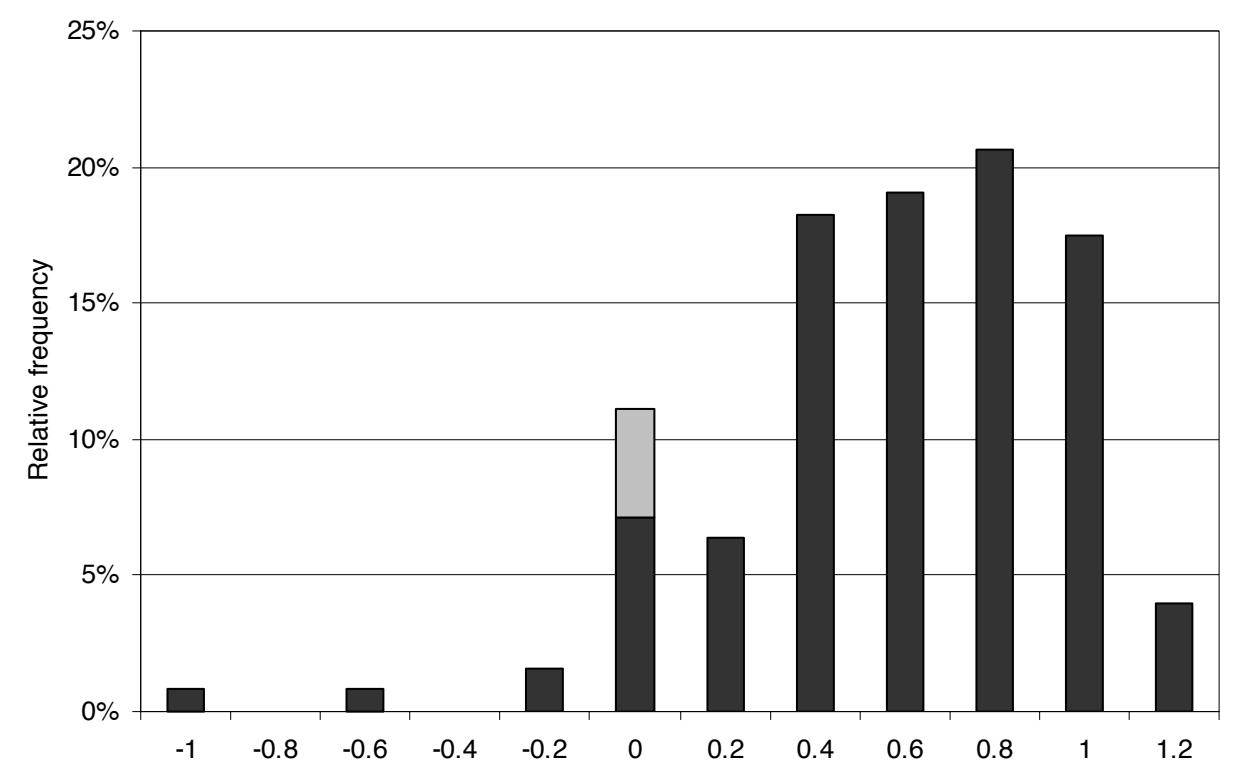

Rounded regression coefficients $\left(c^{1}-c^{2}\right.$ on $\left.g^{1}-g^{2}\right)$ for each individual (periods 2 to 20 )

FIGURE V

SOCIAL INTERACTION EFFECTS AT THE INDIVIDUAL LEVEL

\section{Social interactions and cooperation patterns}

In this final part of the results section we address the following question: Does the fact that subjects are members of two groups significantly affect their contribution behavior? This is an important question since in reality everybody is usually a member of more than one group. Yet, to our knowledge, all public goods experiments performed so far, study the contribution behavior of subjects who are members of just one group. ${ }^{7}$

\footnotetext{
7. There are some public goods studies where subjects could observe what members of another group contributed (e.g., Bardsley and Sausgruber [2003]; Carpenter and Matthews [2003]). In Carpenter and Matthews subjects could even punish members of another group. The goal of these studies is different from ours. Bardsley and
} 
In order to investigate the impact of multiple memberships we compare the contribution patterns of our two-group design with that of a standard one-group design. Parameters in both experiments are exactly identical (see Section II). The only difference is that while subjects make two decisions in two different groups in the two-group design, they make just a single contribution decision in the one-group design. Figure VI shows the evolution of average contributions in both treatments by pooling data from all matching groups.

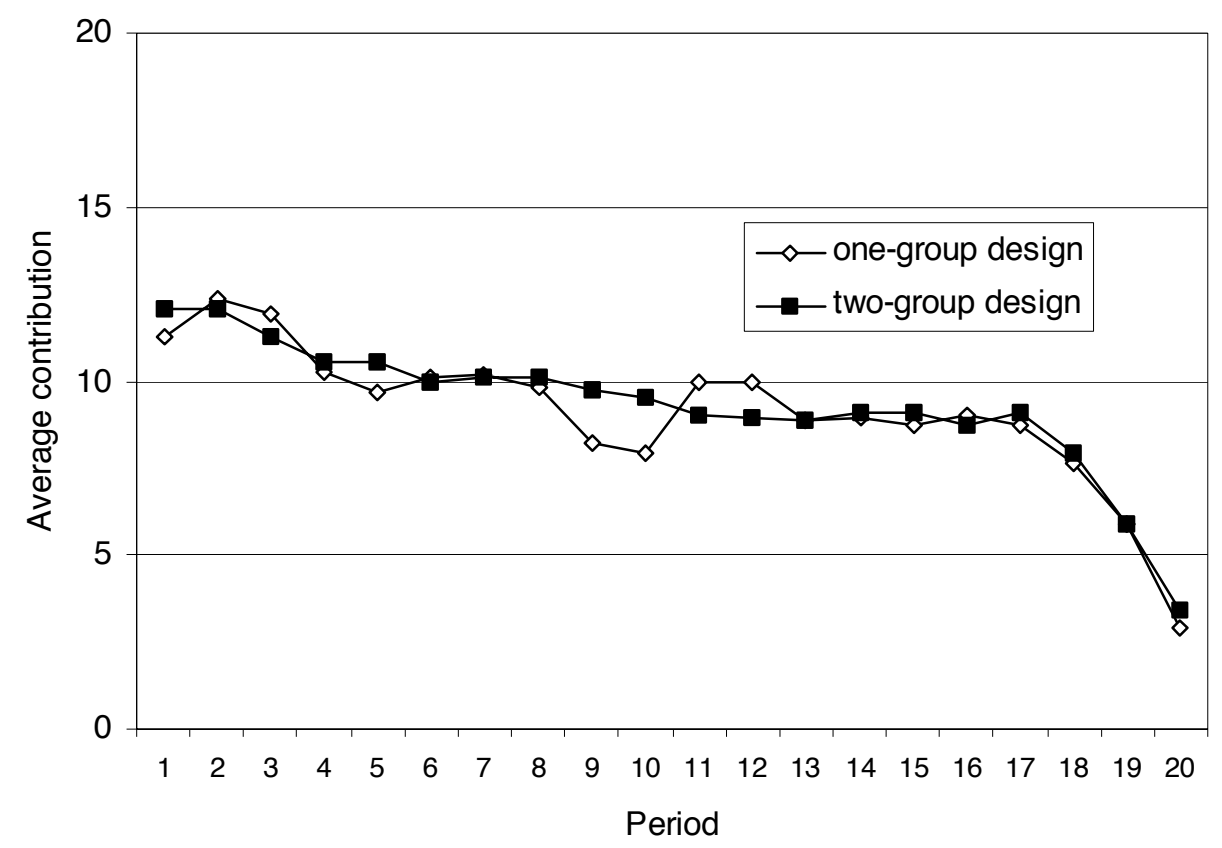

\section{FIGURE VI \\ COOPERATION PATTERNS IN THE TWO-GROUP AND THE ONE-GROUP DESIGN: AVERAGE CONTRIBUTIONS OVER TIME}

The result is striking: The contribution patterns between the two treatments are almost indistinguishable. In both treatments, average contributions start at about 12 tokens (60 percent of the endowment), show a slow downward trend until period 17 and a sharp drop in the final three periods. Final average contribution levels are about 3 tokens (15 percent). A MannWhitney test on matching groups reveals that contributions in both treatments are not significantly different $(\mathrm{p}=1.000)$.

Sausgruber want to disentangle conformism and reciprocity; and Carpenter and Matthews investigate "social reciprocity". 
The results from Figure VI are very informative. The fact that subjects interact in two groups, does not lead to a contribution pattern different from what we usually see in singlegroup public goods experiments. The similarity in contribution patterns is in line with our findings reported in columns 2 and 3 of Table I. Here we saw that the behavior of neighbors from other groups did not significantly influence behavior, i.e., people decide on their contributions on a group level. Methodologically this is good news as it shows that the abstraction to study public goods behavior in games where people are only acting in one group is a good approximation for the behavior in reality, where subject simultaneously interact in more than one group.

\section{CONCLUDING REMARKS}

Identifying social interaction effects is a notoriously difficult task [Manski 1993, 2000]. After reviewing the problems, Manski [1993, p.541] writes: "The only ways to improve the prospects for identification are to develop tighter theory or to collect richer data. (...) Empirical evidence may also be obtained from controlled experiments (...). Given that identification based on observed behavior alone is so tenuous, experimental and subjective data will have to play an important role in future efforts to learn about social effects".

In recent years, the availability of rich microeconomic field data sets has led to considerable progress. In the typical field research paper, identifying a social interaction effect usually amounts to finding a significant coefficient of the group dummy variables (that capture the social groups one is interested in) - after circumventing self-selection problems and after controlling in a multiple regression model for variables that arguably capture the most important correlated and contextual effects. Yet, the approach is only indirect: Any variance that cannot be attributed to the correlated and contextual effects is attributed to social interaction effects. The problem of omitted variables can never be completely circumvented.

In our paper we introduce an experimental design that provides us with direct evidence of social interaction effects in the context of a public goods game. The design has the advantage that it can be easily applied to other games as well, e.g., games with multiple equilibria. By way of our design we directly control for self-selection, and correlated and contextual effects. We have deliberately created an artificial situation in which each subject is a member of two separate, yet economically identical groups with different members. This way, we can ensure 
that each subject simultaneously lives in two identical neighborhoods, where the only possible difference is in the behavior of neighbors, but not in the neighborhood characteristics. Given our tight control, if we observe the same subject contributing differently depending on what the respective neighbors do, we have unambiguous evidence for social interaction effects.

Our results are clear and unambiguous. First, subjects' average contribution behavior is systematically influenced by social interactions. Subjects contribute more to group 1 than to group 2 if the respective neighbors in group 1 contribute more than in group 2 and vice versa. Second, our individual data analysis reveals substantive heterogeneity. Subjects' inclination to display social interactions is very different and roughly 10 percent show no social interactions at all. Finally we show that the fact that subjects interact in more than one group does not lead to a contribution pattern that differs from the one exhibited in a single-group environment. This is an important finding from a methodological point of view. It suggests that studying contribution behavior in single-group designs is appropriate despite the fact that in reality subjects are typically members of many groups.

On a methodological level, our experiment demonstrates the comparative advantage of laboratory experiments in the overarching goal of understanding the phenomenon of social interaction effects. We see field and lab data as complements. Field data sets have the advantage over lab experiments that the former are naturally occurring. Yet, even if the field data are very detailed, evidence of a social interaction effect is only indirect and the drawback remains that in the field one can rarely achieve the tight control that is available in the lab. The lab researcher can even control the game people play, and individual differences can be assessed. Both features are valuable tools in getting at the phenomenon of social interactions effects. 


\section{APPENDIX: EXPERIMENTAL INSTRUCTIONS}

The following instructions were originally written in German. We document the instructions we used in the two-group design. The instructions in the single-group design were adapted accordingly. They are available upon request.

You are now taking part in an economics experiment, which has been financed by various science foundations. If you read the following instructions carefully, you can, depending on your decisions, earn a considerable amount of money. It is therefore very important that you read these instructions with care.

The instructions that we have distributed to you are solely for your private information. It is prohibited to communicate with the other participants during the experiment. Should you have any questions please ask us. If you violate this rule, we shall have to exclude you from the experiment and from all payments.

During the experiment we shall not speak of Francs but rather of Guilders. During the experiment your entire earnings will be calculated in Guilders. At the end of the experiment the total amount of guilders you have earned will be converted to Francs at the following rate:

\section{Guilder = 3 Rappen.}

At the end we will pay in cash the money you have earned during the experiment.

The experiment is divided into different periods. In total, the experiment consists of 20 periods. Every participant is always a member of two groups (group 1 and group 2). Both groups contain 3 participants, that is, besides you there are two further participants in each group. Please notice that the two participants in group 1 are other participants than the two participants in group 2. Therefore, besides you there is no further person who is also a member of group 1 and of group 2.

The composition of the groups will stay the same during the whole 20 periods. Therefore you will be for 20 periods with the same participants in group 1 and in group 2. The following pages describe the course of the experiment in detail:

\section{Detailed Information on the Experiment}

At the beginning of each period each participant receives 20 points for group 1 as well for group 2. In the following we call this his or her endowment. Your task is to decide how to use your endowment. You have to decide in group 1 as well as in group 2, how many of your 20 points you want to contribute to the project and how many you want to keep for yourself. 
Your period income in a group depends on how many points you contribute to the project and how many points are contributed to the project by the two other participants. Your income in a group consists of two parts:

(1) The points which you have kept for yourself ("Income from points kept") whereby $\mathbf{1}$ point = $\mathbf{1}$ Guilder, and

(2) The "income from the project". This income is calculated as follows:

Your income from the project $=$

$0.6 \mathrm{x}$ the total contribution of all group members to the project.

Your income per period in group 1 or group 2, respectively, is therefore:

$(20$ - your contribution to the project $)+0.6 *($ total contributions to the project $)$.

The income of each group member from the project is calculated in the same way. This means that each group member receives the same income from the project. Suppose the sum of contributions of all group members is 50 points. In this case each group member receives an income from the project of $0.6 * 50=30$ Guilders. If the total contribution to the project is 8 points, then each group member will receive an income of $0.6 * 8=4.8$ Guilders from the project.

For each point, which you keep for yourself you earn an income of 1 Guilder. Suppose you contributed this point to the project instead. The total contribution to the project would then rise by one point. Your income from the project would rise by $0.6^{*} 1=0.6$ points. However, the income of each other group member would also rise by 0.6 points each, so that the total income of the group would rise by $0.6 * 3=1.8$ points. Your contribution to the project therefore also raises the income of the other group members. On the other hand you earn an income for each point contributed by the other members to the project. For each point contributed by any member you earn $0.6 * 1=0.6$ points.

\section{The calculation of incomes is exactly the same in group 1 and group 2.}

At the beginning of each period the following input screen will appear: 


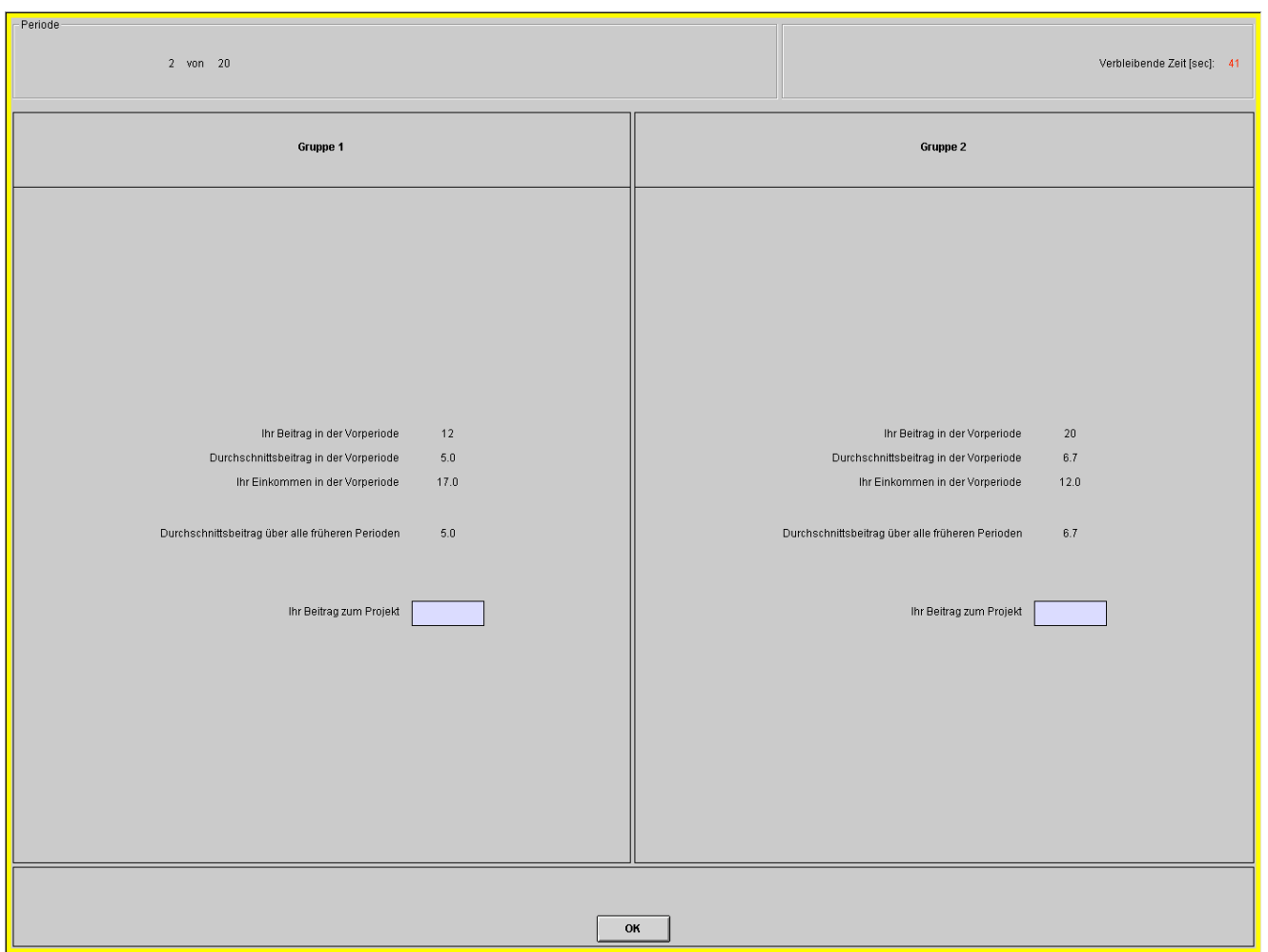

In the top left corner of the screen appears the period number. In the top right corner there is a clock in seconds. It shows how much time remains for you to make a decision on the distribution of your points.

The screen is divided into two parts. On the left, you find the information concerning group 1, and on the right the information for group 2. First you can see the amount you have invested into the project in the previous period ("Your contribution in the previous period"). Beneath you find the average contribution of the respective group in the previous period. If in the previous period the contributions of the three group members have been, for instance, 10,15 and 20, the number beside "average group contribution in the previous period" will be 15 . Beneath you will find your income in the previous period.

A bit further down you can see the "average group contribution of all previous periods". This number shows the total average contribution of all group members of a respective group over all previous periods. If, for example, the average contribution in period 1 were 3 , in period 2 it were 2 and, e.g., 1 in period 3 , in the fourth period the number in this line would be 2. The "group average contribution over all previous periods" is therefore a short summary of the previous history in a group. The higher the average contribution in a group has been up to now, the higher the value in this line will be.

Still a bit further down you can enter your contribution. As already mentioned, your endowment in each of the two groups will always be 20 points. You choose in each of the two groups your contribution for each group, by entering a number between 0 and 20 in the particular window. You can activate this window with a mouse-click. As soon as you have defined both of your contributions, you have also decided how many points you are going to keep for yourself, that is to say (20 - your contribution). If you have entered your contribution in both groups, 
you have to press the OK-button (mouse-click). As long as you have not pressed the OK-button, you can still revise your decision in this period.

Please notice: group 1 and group 2 are two totally independent groups. Therefore you can make your contribution decisions in group 1 and group 2 absolutely independently from each other, i.e., you decide separately for both groups. Your contribution in group 1 can be higher, equal or lower than your contribution in group 2. You have an endowment of 20 points in each group and each period.

Remark: In the first period your screen contains only the possibility to choose your contribution. Since in the first period there is no previous period and therefore further information (like "your contribution in the previous period") cannot yet be shown.

After all group members have made their decisions, a period is over. After that you get back to your input screen. On this screen you can see the contributions of the previous period of both groups and your income in both groups. You can also see the average contribution of both groups up to now. You can then make your new contributions in group 1 and group 2. In total there are $\mathbf{2 0}$ periods. Do you have any questions?

\section{Control questionnaire}

Please answer all the questions and write down the whole calculation process. If you have any questions please contact us!

\section{1st Question}

In group 1 neither you nor the other participants contribute to the project.

In group 2 you contribute 20 points and also the other group members contribute 20 points. What is

Your income in group 1 ? ...

The income of the other members in group 1 ? ...

Your income in group 2? ...

The income of the other members in group 2 ?...

\section{2nd Question}

In group 1 all the members together contribute totally 30 points to the project.

In group 2 also all the members contribute totally 30 points to the project. What is

Your income in group 1, if you contribute 10 points on top of the 30 points? ...

Your income in group 2 , if you contribute 0 points on top of the 30 points? ...

\section{3rd Question}

In group 1 you contribute 16 points to the project. What is

Your income in group 1, if the other participants contribute 34 points on top of the 16 points? ...

Your income in group 1, if the other participants contribute 4 points on top of the 16 points? ... 


\section{REFERENCES}

Akerlof, George, "Social Distance and Social Decisions.” Econometrica 65(4) (1997), 10051027.

Andreoni, James, "Impure Altruism and Donations to Public Goods: A Theory of Warm Glow Giving.” Economic Journal 100 (1990), 464-477.

Andreoni, James, "Warm-Glow versus Cold-Prickle: The Effects of Positive and Negative Framing on Cooperation in Experiments." Quarterly Journal of Economics 110(1) (1995a), 1-21.

Andreoni, James, "Cooperation in Public Goods Experiments: Kindness or Confusion?" American Economic Review 85(4) (1995b), 891-904.

Bardsley, Nicholas, and Rupert Sausgruber, "Social Interaction Effects in the Laboratory and Society: Conformism and Reciprocity in Public Good Provision", mimeo, University of Nottingham 2003.

Bertrand, Marianne, Erzo Luttmer, and Sendhil Mullainathan, "Network Effects and Welfare Cultures." Quarterly Journal of Economics 115(3) (2000), 1019-1055.

Carpenter, Jeffrey P., and Peter H. Matthews, "Social Reciprocity", Mimeo, Middlebury College 2003.

Case, Anne, and Lawrence Katz, "The Company You Keep: The Effects of Family and Neighborhood on Disadvantaged Youths.” NBER Working Paper No. 3705, 1991.

Coleman, James, Foundations of Social Theory. (Cambridge, MA: The Belknap Press of Harvard University Press, 1990).

Croson, Rachel, "Theories of Commitment, Altruism and Reciprocity: Evidence from Linear Public Goods Games". OPIM Working Paper, Wharton School of the University of Pennsylvania 1998.

Falk, Armin, and Andrea Ichino, "Clean Evidence on Peer Pressure.” Working Paper No. 144, Institute for Empirical Research in Economics, University of Zurich, 2003.

Fischbacher, Urs, "z-Tree. Zurich Toolbox of Readymade Economic Experiments." Working Paper Institute for Empirical Research in Economics, University of Zurich, No. 21, 1999. Fischbacher, Urs, Simon Gächter, and Ernst Fehr, “Are people conditionally cooperative? Evidence from a public goods experiment." Economics Letters 71 (2001), 397-404. 
Glaeser, Edward, and José Scheinkman, "Measuring Social Interactions.” In: Steven Durlauf and Peyton Young (eds.): Social Dynamics. (Cambridge, M.A.: The MIT Press, 2001).

Glaeser, Edward, Bruce Sacerdote, and José Scheinkman, "Crime and Social Interactions." Quarterly Journal of Economics 111 (1996), 507-548.

Ichino, Andrea and Giovanni Maggi, "Work Environment and Individual Background: Explaining Regional Shirking Differentials in a large Italian Bank." Quarterly Journal of Economics 115(3) (2000), 1057-1090.

Katz, Lawrence, Jeffrey Kling, and Jeffrey Liebman, "Moving to Opportunity in Boston: Early Results of a Randomized Mobility Experiment.” Quarterly Journal of Economics 116(2) (2001), 607-654.

Keser, Claudia, and Frans van Winden, "Conditional Cooperation and Voluntary Contributions to Public Goods." Scandinavian Journal of Economics 102(1) (2000), 23-39.

Ludwig, Jens, Gregg Duncan, and Paul Hirschfield, "Urban Poverty and Juvenile Crime: Evidence from a Randomized Housing-Mobility Experiment." Quarterly Journal of Economics 116(2) (2001), 655-679.

Manski, Charles, "Identification of Endogenous Social Effects: The Reflection Problem." Review of Economic Studies 60 (1993), 531-542.

Manski, Charles, "Economic Analysis of Social Interactions." Journal of Economic Perspectives 14(3) (2000), 115-136.

Palfrey, Thomas, and Jeffrey Prisbrey, “Anomalous Behavior in Public Goods Experiments: How Much and Why?” American Economic Review 87(5) (1997), 829-846.

Sacerdote, Bruce, "Peer Effects with Random Assignment: Results for Dartmouth Roommates.” Quarterly Journal of Economics 116(2) (2001), 681-704.

Sugden, Robert, "Reciprocity: The Supply of Public Goods Through Voluntary Contributions", Economic Journal 94 (1984), 772-787. 